\title{
SPACE-TIME FORMATIONS IN THE SOUTH INDIAN TAMIL POPULAR FILM KANNATHIL MUTHAMITTAL
}

\author{
Ramesh Loganathan* \\ Faculty of Social Sciences and Humanities, Universiti Kebangsaan Malaysia, \\ 43600 UKM Bangi, Selangor, Malaysia \\ e-mail: rameshlogan@siswa.ukm.edu.my \\ Shanthini Pillai** \\ Faculty of Social Sciences and Humanities, Universiti Kebangsaan Malaysia, \\ 43600 UKM Bangi, Selangor, Malaysia \\ e-mail: spillai@ukm.edu.my \\ Pramela Krish ${ }^{* * *}$ \\ Faculty of Social Sciences and Humanities, Universiti Kebangsaan Malaysia, \\ 43600 UKM Bangi, Selangor, Malaysia \\ e-mail: pramela@ukm.edu.my
}

Published online: 15 July 2018

To cite this article: Loganathan, R., Pillai, S. and Krish, P. 2018. Space-time formations in the South Indian Tamil popular film Kannathil Muthamittal. International Journal of Asia Pacific Studies 14 (2): 143-164, https://doi.org/ 10.21315/ijaps2018.14.2.7

To link to this article: https://doi.org/10.21315/ijaps2018.14.2.7

\begin{abstract}
In tandem with the current development of film scholarships in the area of the world and national cinemas, the paper seeks to examine four scenes from the South Indian Tamil popular film "Kannathil Muthamittal" (English: A Peck on the Cheek) using a concept derived from Hamid Naficy's theorisation of an accented cinema known as the filmmakers' "preoccupation with the place." The conception is cinematically expressed through spatial representations of the open, closed and the third spacetime formations. In the accented cinema, space-time formations are cinematic spatial aspects that are employed to produce or reproduce the fundamental "accent" of displacement and deterritorialisation. According to Naficy, the accent predominantly originates from the filmmakers' experiences and their artisanal productions and not so much from their accented lingo. The paper, in particular,
\end{abstract}


aspires to engage critically the national film "Kannathil Muthamittal" directed by the renowned Indian filmmaker, Mani Ratnam. The paper will evidentially establish that the accented cinematic features which are exclusive to the accented cinema have consistently appeared in the selected scenes in the film. Although Naficy's theory has offered a range of cinematic features that express the filmmakers 'preoccupation with the spaces and places they inhabit and their displacement and deterritorialisation experiences, the paper will only concentrate on the spatial representations of the open, closed and the third space-time formations. As for the accented filmmakers, the theory of an accented cinema distinguishes the accented filmmakers into three distinct categories, namely the diasporic, the exilic and the postcolonial ethnic. Even though it is obvious that director Mani Ratnam does not belong to any of these groups, the cinematic style and strategies employed in Kannathil Muthamittal, especially in the selected scenes, exhibit the visual and the narrative markers of the accent. By examining the style and the strategies employed in these scenes, the paper concludes that the South Indian Tamil cinema has indeed embarked on a path that puts it ahead from its conventional style to a more advanced form of filmmaking which integrates a broad range of cinematic features employed from various other forms of cinemas.

Keywords: Accent, space-time formation, spatial representations, preoccupation, cinematic, displacement and deterritorialisation

\section{INTRODUCTION}

The film Kannathil Muthamittal (directed by Mani Ratnam 2002) enjoyed its maiden premier at the 2002 Toronto International Film Festival. The following year, the film received an overwhelming reception at the San Francisco International Film Festival. The film continued to receive high critical acclaim and went on to win the "Best Film category awards at six international film festivals, six best film National Film Awards and six best South Indian Filmfare Awards" (Dhananjayan 2014: 414). Although Kannathil Muthamittal may appear to be like any other regular south Indian Tamil film, certain cinematic attributes that are evidently present in the film distinguishes it from the other south Indian Tamil films. Apart from the popular stereotypical cinematic elements of Indian cinema, namely, romance, comedy, scenery, songs, culture, melodrama and suspense, the film expresses the displacement and the deterritorialisation of the Eelam-Tamils of Sri Lanka as how an accented film would illustrate such troubling issues. Reasoning from this fact, it is evident that Kannathil Muthamittal is not of the accented make, and the filmmaker Mani Ratnam is not from the accented filmmaking fraternity. 
Nevertheless, four scenes from the film strongly exhibits the dynamics of the accented style of filmmaking.

Besides the trauma of forced evacuations and forced expulsions, the subject of displacement and deterritorialisation in the film is established through the portrayals of two main landscapes. The coastal town of Rameswaram in Tamil Nadu, India, and the native Eelam-Tamil homeland of Sri Lanka. In the film, both the settings highlight the notion of home, unhomeliness and home seeking affiliations. In the four scenes, both the landscapes, Tamil $\mathrm{Nadu}$ and the Eelam-Tamil homeland play a crucial role in expressing the accent of the Eelam-Tamil displacement and deterritorialisation. Naficy argues that the accent exclusively stems from the filmmakers' displacement and deterritorialisation experiences and not so much from their spoken lingo (Naficy 2001: 4). Coming from Naficy's explication of the accent, Subeshini Moodley argues that the accent also stems from the various factors that had influenced the filmmakers' physical and psychological displacement (Moodley 2003: 66). For instance, filmmaker's origin, causes of displacement, the period involved and the filmmakers' geographical background, their alternative production modes, filmmaking styles and strategies. Fundamentally, the accent is the main criterion that distinguish the accented cinema from the other forms of cinema.

\section{THE ACCENTED FILMS}

The dominant cinema which has long established itself as a large-scale entertainment industry is made of national, or the world films, these films are considered universal and without accent. Conversely, the accented cinema which is really a conglomeration of diasporic, exilic and postcolonial ethnic film is characteristically "interstitial because these films are created astride, and in the interstices of social formations and cinematic practices" (Naficy 2001: 4-5). Though Kannathil Muthamittal is inherently a commercial film of the national produce, the film, however, shoulders the subject of displacement and the deterritorialisation of the Eelam-Tamils. The four selected scenes not only render the forced evacuation of the Eelam-Tamils from the native villages, but also the effects of forced external expulsion. One such example is the portrayal of the refugee camp in Rameswaram, Tamil Nadu, India. Therefore, Kannathil Muthamittal is a national film that unequivocally reflects much of the accented cinematic works.

Of late, the accented filmmaking strategies have certainly gained grounds in the cinema world. The genre had indeed grown immensely 
in terms of output, stylistic variety, cultural diversity and social impact. Many contemporary world and national filmmakers are known to have incorporated the accented filmmaking strategies in their works. In her acclaimed work, Asuman Suner (2006) identifies three prominent national filmmakers who have resorted to the accented filmmaking strategy to render the effects of displacement and deterritorialisation. Among them are the KurdishIranian director Bahman Ghobadi who produced the film, A Time for Drunken Horses (Zamani barayé masti asbha, dir. Ghobadi 2002), Hong Kong director Wong Kar-Wai's Happy Together (Chun gwong cha sit, dir. Kar-wai 1997) and Turkish director Nuri Bilge Ceylan's Distant (Uzak, dir. Ceylan 2002). The works of these filmmakers evidently reflect much use of the accented strategies employed as narrative tools that produce or create the accent to render cinematic portrayals of displacement and deterritorialisation. In the same way, director Mani Ratnam, an acclaimed Indian national filmmaker had resorted to the use of accented filmmaking strategies, in a few scenes, to create the accent that expresses the Eelam-Tamil displacement and deterritorialisation in Kannathil Muthamittal.

\section{THE PLOT}

The film's central plot develops around a nine-year-old girl, Amudha. On her ninth birthday, Amudha comes to know that she was an adopted child. Eventually, Amudha develops a strong yearning to find out who her actual parents were and why she was given away for adoption. The only information that she was able to obtain is a name, M. D. Shyama, the name of her biological mother, an Eelam-Tamil refugee who came from Sri Lanka. After many struggles and persuasions, with her adoptive parents, Amudha reaches the native Eelam-Tamil homeland of Sri Lanka in search of her biological mother. In the film, Shyama is portrayed both as a strong mother and a devoted Eelam fighter. She leaves her new-born baby, Amudha, at the Rameswaram refugee camp in India and returns to the Eelam enclave of Sri Lanka where she continues to fight for the liberation of the native Eelam-Tamil homeland. On her arrival, Amudha becomes terrified of the civil war-trodden environment. Being a child who does not even know the meaning of civil war, Amudha struggles to comprehend the trauma and the adversities of the civil war predicament.

The subsequent plot is mainly about how Amudha reunites with her biological mother. Though the plot appears to be rather emotive and predictable, the accent of displacement and the deterritorialisation is certainly convincing. 
In the film, the accent is illustrated through the portrayals of the civil war environment. Director Ratnam's screenplay which effectively depicts the severity of the Sri Lankan civil war through the representations of both the landscapes also draws attention to an emotive storyline that revolves around the life of an estranged mother who is torn between the love for her homeland and her only child. The final scene is evidently all about appeasement. The mother-child appeasement takes place in an environment where guns were being fired in every direction, this is the scene where Amudha finally realises that she has to let her mother go for the greater good.

Although the film's plot resembles the one of the accented, yet, for the most part, the film retains the signature filmmaking style of South Indian Tamil cinema. The distinct style is exclusively characterised by extravagant productions and sweeping epic melodrama interspersed with haunting songs. Even though the film has exploited one or two familiar themes of South Indian Tamil cinema, namely, the mother-child sentiments, the film remains as an exception to South Indian Tamil cinema. According to Dhananjayan (2014), Ratnam's work in Kannathil Muthamittal is indeed commendable as he had put much effort in rendering the struggles of the Eelam-Tamils as authentically as possible (Dhananjayan 2014: 412). The realism of displacement and deterritorialisation is effectually presented through dark and cold cinematic ambiences. Besides that, the spatial representations shown in these scenes appear to be specially configured to express the trauma and the pain of displacement and deterritorialisation of the Eelam-Tamils. It needs to be highlighted that the strategy of producing and reproducing meaning through visual-spatial representations is somewhat new to South Indian Tamil cinema.

\section{SOUTH INDIAN TAMIL CINEMA}

Over the years, South Indian Tamil cinema has established itself as an integral part of the economic, social, cultural and political construct of Tamil Nadu. Sundararaj Theodore Baskaran writes, "over seventy-nine years of its existence, Tamil cinema has grown to become the most domineering influence in the cultural and political life in Tamil Nadu" (Baskaran 1996: ii). In these years, Tamil films have immensely focused on the representations of the South Indian Tamil homeland through its social, political and cultural landscapes. The Neonativity film era of South Indian Tamil cinema, that is the 70s and the 80 s, saw most south Indian Tamil filmmakers employing village and rural landscapes of Tamil Nadu as the preferred sites for their films. According to Velayutham (2008), in the 90s, most Tamil filmmakers shifted their orientation towards 
the urban space or the city landscapes as the primary backdrop for their films (Velayutham 2008: 4). Many prominent South Indian Tamil filmmakers were also known to have exploited locations outside of Tamil Nadu as the primary backdrops for their films. The landscapes of the native Tamil homeland of Sri Lanka were once the preferred locations for numerous South Indian Tamil films. However, due to the civil war situation that lasted for almost three decades, the Eelam-Tamil homeland of Sri Lanka has yet to receive the kind of cinematic attention that is being relished by Tamil Nadu, the Tamil homeland of South India.

In most South Indian Tamil films, the filmmakers' sense of thematic preoccupation has been well represented in terms of its expressive landscapes that render the political, social and cultural environments of the Tamil homeland. According to Pandian (2011), the spatial representations of the Tamil homeland rendered in Tamil cinema are "often invested with power and affective quality" (Pandian 2011: 61). Pandian also argues that in the efforts to maintain or to fortify the effects of power and affective quality, "cinema draws its vitality from affective encounters with many kinds of worlds" this creates a "situation" of "qualitative overspill, a fabricated environment of encounter, resonance, and excess" (Pandian 2011: 52-53). Pandian's argument unequivocally refers to the affective song-sequences scenes that deploy exotic foreign landscapes and the films that rely on reinvented local landscapes to render the required affectiveness. In his study on the cinematic landscapes of South Indian Tamil films, Pandian concludes that "less the fixing of spatial contexts for the framing of feeling, and more the fluid processes through which affects come to inhabit a world" (Pandian 2011: 74). Pandian's study proves that the sense of preoccupation in South Indian Tamil films is primarily configured towards affective expressions rather than artistic representations. However, director Ratnam happens to be a prominent national filmmaker has proved Pandian otherwise; through Kannathil Muthamittal, Ratnam has shown to the south Indian Tamil cinema that the accent can be artistically reproduced to express the accent of displacement and deterritorialisation on the screen.

\section{THE NON-ACCENTED FILMMAKER}

According to Baskaran (1996), the South Indian Tamil cinema has certainly come a long way in the last seventy-nine years and has emerged as a robust film industry of South India (Baskaran 1996: 1). Over the years, Tamil cinema has certainly made its presence known in the global film arena. Apart from 
producing world-class Tamil films, the South Indian Tamil cinema has also given many legendary talents who have taken the Tamil films to the international screens. Amongst them stands Gopala Ratnam Subramaniam (widely known by his screen name Mani Ratnam), an Indian national film auteur, screenwriter and producer who predominantly works in the South Indian Tamil cinema. Nagappan (2011) argues that Mani Ratnam's films are products of Chennai, Tamil Nadu and not Mumbai or the Hindi language (Nagappan 2011: 170).

Mani Ratnam's brand of Tamil films have created waves in the world cinemas, having won many acclaimed film awards. Ratnam is celebrated as one of the greatest film talents of India. Besides, Ratnam's distinctive filmmaking style has given a fresh breath to the Indian filmmakers, particularly, South Indian Tamil filmmakers. The distinctiveness in most of his films is certainly rendered through the illustrations of the Tamil "native-ness," affective expressions, art and realism. Ratnam's films are distinctly recognised through exclusive cinematic features, to name a few, dim lighting, short dialogues, realistic backgrounds, song picturisations and strong female characters. "Ratnam's films have marked the renaissance of the Tamil cinema, viewers flocked to his more complex characters, his innovative use of the camera and of course the lively music" (Nagappan 2011: 172).

Unlike the accented filmmakers who deliberately break away from the practices of profit-motivated film industries, Ratnam, throughout his career as a mainstream filmmaker, has produced films that have found the right balance of commercial and artistic sensibilities. For instance, Ratnam's impactful films such as Roja (dir. Mani Ratnam 1992) and Bombay (dir. Mani Ratnam 1995), although both the films evidentially express the national importance, political turmoil and human relationships, both the films were hailed as a critical and commercial success. "Ratnam's films demonstrate a potent 'middle cinema' - a cinema that bridges the seemingly insurmountable divide between Indian popular and art film" (Nagappan 2011: 172). Through most of his films, Ratnam has made a clear stand by addressing issues that are current and relevant to the Tamil society, Ratnam films are "rooted in the Tamil language and exalt the Tamil culture" (Nagappan 2011: 170). The highly acclaimed Kannathil Muthamittal is one such effort, one of the main highlights of the film is the emotional and cultural bond between the Tamils of Tamil Nadu and the Eelam-Tamils of Sri Lanka.

In the film, director Mani Ratnam explores a highly controversial yet significant issue of the Eelam-Tamil minority ethnic of Sri Lanka. The film renders the initial phase of the post-civil war environment in the Eelam-Tamil homeland of Sri Lanka through the eyes of his young protagonist, Amudha, 
a nine-year-old Tamil girl who comes from a coastal town in Rameswaram, Tamil Nadu. The film maintains the commercial aspects of a South Indian Tamil feature film and at the same time expresses the conflict in the EelamTamil homeland in an artistic manner. Prominent Indian film critic, Maithili Rao regards Mani Ratnam as the man who is responsible for "redefining the range and depth of Tamil cinema" (NFDC 1991: 18). The 2002 film is about relationships and how these relationships are affected by the civil war in Sri Lanka. Besides all the other glamorous attributes of the dominant or national cinema, the depth of this film lies in how Ratnam explores the issues of displacement and deterritorialisation using the accented filmmaking mechanisms. The most assuring is the employment of the cinematic features that create the filmmakers' accent of displacement and deterritorialisation.

\section{THE PREOCCUPATION WITH THE PLACE AND THE ACCENT}

As one of the central concepts delineated in the theorisation of an accented cinema, the preoccupation with the place expresses the accented filmmakers' emotional bond with the past, and the present and the loved, and the hated homeland. The concept also reveals the filmmaker's "utopian yearning for faraway utopian places, homesick nostalgia for the past, the schizoid perception of the present, loss of identity and belonging, and desire for social others and foreigner" (Naficy 2001: 206). It also needs to be stressed that in the accented filmmaking system, the accent which cinematically reveals the effects of displacement and deterritorialisation only emanates from the filmmakers' experiences and their preoccupation with the spaces and places they inhabit.

Based on the distinctiveness of the accent, the theory an accented cinema classifies the accented filmmakers into three distinct categories, that is, the diasporic, exilic or post-colonial ethnic. The classifications also reflect the filmmakers' background, particularly their ethnicity, national identity and the form of expulsion they have experienced, either forced or volunteered. Naficy's book primarily concentrates on filmmakers from different parts of the world, mainly from the Latin America, Lithuania, Iran, Turkey, Palestine and Russia. Naficy (2001) argues that in terms of the experiences of displacement and deterritorialisation, all the accented filmmakers vary extensively, this also includes their psychological displacements (Naficy 2001: 10). Conclusively, Naficy stresses that one should never assume that the accented filmmakers are not all equally or similarly displaced or deterritorialised. Based on Naficy's in-depth explication of the accent, it is evident that director Ratnam does not belong to any of the accented classifications. However, in Kannathil 
Muthamittal, Ratnam exploits the accent merely as a narrative strategy that creates the exilic environment and predicament. The strategy proves to be the film's greatest strength as the cinematically concocted accent effectively sets up the required frames for the film's dramatic climax which brings the estranged mother and daughter together.

Ratnam's exploitation of the accent as the means of using it only as a cinematic strategy is certainly evident in the film's treatment of nostalgia. In the film, the nostalgia which is a significant aspect of the accent is mostly rendered through the settings of the native Eelam-Tamil homeland of Sri Lanka. One such scene that evokes the sense of nostalgia is the scene that shows Thiruchelvan and Harold Wickramasinghe walking through an open field. In this scene, the sense of nostalgia does not express any sense of preoccupation nor the experiences of displacement and deterritorialisation, and it is only used as a strategy to reveal the natural environment of the native Eelam-Tamil homeland of Sri Lanka. Similar scenes like this can be seen at the beginning and ending parts of the film. Nevertheless, the strategy effectively reproduces the muchneeded exilic spatial and temporal atmosphere. However, the employment of the accent as a cinematic strategy is indeed an obvious distinction between the commercial and the accented cinema. In fact, in most commercial films, especially the recent ones, the accent is mainly exploited and employed as a cinematic tool that produces the required effects according to the needs of the film's plot. The accented films, on the other hand, are firmly focused on conveying authentic or encrypted meanings and messages. Probably due to the concerns of authenticity of the accent, Kannathil Muthamittal did not escape from criticism. However, the acclaimed film remains as the first of its kind that has successfully employed the artistic strategies to produce meaning through spatial representations.

The following scenes in the film patently demonstrate the manifestation of the accent: The first scene depicts Dhileepan and Shyama's separation. The second scene depicts the capture of Thiruchelvan and Dr. Harold Tamil by the Tamil rebels. The third scene portrays the refugee camp at Rameswaram, and the fourth scene presents the ancestral Tamil homeland in Sri Lanka. As mentioned earlier, Ratnam's distinct filmmaking style combines both aesthetic and commercial aspects of cinema. The selected four scenes are inherently aesthetic, these scenes express realistic conditions and do not involve sequences and situations that are irrelevant to the plot. Although the other scenes in the film are imperatively relevant to the plot, they are very much commercially fashioned, these scenes involve grand settings, comedy, romance, songs, dances and exotic locations. The mise-en-scène of the selected scenes revolves 
around the intense experiences of space and time which can be examined using Naficy's spatial representation modality. The modality plays a crucial role in defining the spatial and temporal characteristics of accented spaces and landscapes through the open, closed and third space-time formations. The outcome of this analysis would reveal how the accented feature, predominantly, the spatial representation modality had been used as a strategy to produce the accent in a national-commercial film. The spatial representation modality operates as the accented feature that presents the space or the place and also as the artistic expression that reveals "the intrinsic connectedness of temporal and spatial relationships that are artistically expressed in literature" (Bakhtin, Holquist and Emerson 2010: 84).

Naficy uses the spatial representation modality as the "unit of analysis for studying texts in terms of their representation of spatial configurations and as an 'optic' for analysing the forces in the culture that produce these configurations" (Naficy 2001: 152). The modality functions as an accented device that primarily analyses the cinematic spatial representations. Among other things, the modality also expresses the filmmakers' preoccupation with the place and functions as an analysing mechanism that examines the connection between "inherited space-time of the homeland to the constructed space-time of the exile and diaspora" (Naficy 2001: 152). The modality, through the space-time formations, demonstrates how the spatial representations of the homeland in the conditions of, either the diasporic, exilic or postcolonial ethnic setting, is cinematically conveyed through the open, closed and third space-time formations. All the three space-time formations are inherently place bounded, these formations refer "to certain specific temporal and spatial settings in which stories unfold" (Naficy 2001: 152).

\section{SPACE-TIME FORMATIONS: THE OPEN, CLOSED AND THE THIRD}

The most important role of accented films is to express and to demonstrate the filmmakers" yearnings for a "utopian prelapsarian space-time" of the imagined homeland that is uncontaminated by "contemporary facts" (Naficy 2001: 152). Such ideal places refer to the pre-displacement phases where the filmmakers often desire for an ideal homeland that is luxuriant and liberated. Such desires are cinematically expressed through the wide and open view of a particular landscape which is usually conveyed through long and mobile camera shots. The attributes of the open space-time formations consist of cinematic aspects such as "external locations and open settings and landscapes, bright natural 
lighting, and mobile and wandering diegetic characters" (Naficy 2001: 153). External locations, open settings and landscapes are favoured aspects that are used as the representations of the desired vision of the homeland. Representations such as these are usually conveyed as pictorial, liberated and extensive visuals on the screen. The use of bright natural lighting is considered as the signature feature of the accented filmmaking strategy. The open-space time scenes are stringently composed using natural sunlight as the predominant lighting scheme.

Another significant aspect of the open space-time formation is the prevailing existence of the diegetic characters. Gerald Prince (2003) states that unlike the conventional characters, the "diegetic character narrates, tells or recounts the story and summarises and makes comments on the events that make up the film's plot, these actions are usually conveyed through the narrator thoughts" (Prince 2003: 1984). The closed space-time formations are inherently characterised by the filmmakers' preferences of filming in spaces that convey the idea restriction and confinement. In the accented films, the manifestations of the closed space-time formations are mostly represented through the urban or oppressive landscapes. According to Fowler and Helfield (2006), urban landscapes are also seen as spaces that delimit, rather than amplify the opportunities for growth. The urban landscapes also "express a strong sense of claustrophobia: compressed and clogged with the detritus of city life" (Fowler and Helfield 2006: 3). The closed space formations also represent the sense of physically or metaphorically imprisonment and oppression. The characters involved are often shown experiencing "restrictions in movements and perspectives by spatial, bodily, or other barriers" (Naficy 2001: 153). The condition is usually revealed through "tight shot composition, static framing, and barriers' and shots that focus on closedness" (Naficy 2001: 153). The mise-en-scène of the closed spacetime formations mainly consists of "interior locations and closed settings, such as prisons and tight living quarters, a dark lighting scheme that creates a mood of constriction and claustrophobia" (Naficy 2001: 153). According to Christopher Gow (2011), the third space-time formations inherently represent the structures of slip zones. Gow claims that slip zones are formed through the decussation of the open and the closed space-time formations (Gow 2011: 70). In agreement with Gow, Lance Hanson (2009) asserts that the third spacetime formation is a spatial structure that combines both the features of the open and closed formations and they are "characterised by the narratives of transition and liminality" (Hanson 2009: 7). Naficy argues that the third spacetime formations are also the spaces that best illustrate the "characteristics of 
exile" (Naficy 2001: 212). The ethos of those who occupy these spaces are no longer fixated on originality. Those who inhabit or occupy these spaces or zones "are presented not discretely but in a structure of play of sameness and difference, of authenticity and translation" (Naficy 2001: 213). In the accented films, the third-space formations are the representations of transitional and transnational spaces such as travel, crossings, border spaces and journeys. The common manifestations of the third space-time formations are "borders, tunnels, seaports, airports, and hotels or means of transportation, such as trains or buses" (Naficy 2001: 5).

As the projectors of cinematic spatial structures in accented films, spacetime formations do not always function as exclusive features. For instance, there could be a few scenes in a film that are composed using a single spacetime formation while other scenes using multiple formations. Naficy argues that there are possibilities where all three formations may at times "reinforce, coexist with, or contradict one another" (Naficy 2001: 153).

\section{THE OPEN SPACE-TIME FORMATION}

The construction of the open space-time formation is consistently evident in the setting where Dhileepan and Shyama are seen together at the river. The plot begins in Maankulam, a small village in the northern province of Sri Lanka where its population is made out of the Eelam-Tamil ethnic minority. The first scene depicts Dhileepan and Shyama's separation. The scene opens with a medium shot angle which brings to view the setting of a river amidst greeneries, the reflection of the sun on the water indicates the brightness of the sun. In accented films, sunlight is an indicator of time. Thickets, greeneries and sunlight are essential markers that exemplify the magnificence and lushness of the land in question. In terms of the artistic expressions of the open spacetime formation, markers of nature are important features that complement and reinforce the open space-time formations. The scene reveals the abundance of happiness surrounding both Dhileepan and Shyama. The mise-en-scène establishes the open space-time formation through the view of the river in broad daylight, amidst the green surroundings. The following manifestation of the open space-time formation can be seen in the subsequent part of the scene where both Dhileepan and his wife Shyama express their attachment and affection towards their homeland. The sense of the openness is further established in the part where Dhileepan and Shyama are shown smearing soil 
in each other's face. Although this part of the scene goes without any dialogues, the sense of openness is established through both the characters' love for the soil. Here, Ratnam uses the soil as a cinematic metaphor to establish the particular space and place as a "potent symbol of the homeland" (Taylor 2015: 97).

The open space-time formation is also discernible in the second scene where both characters, Thiruchelvan and Harold Wickramasinghe, are shown walking through a vast open field, presumably in a rural area, this particular frame comes before they were attacked by a group of Tamil rebels. The view of the field is presented through the use of mobile long and medium shots and bright natural lighting. Based on Naficy's description of the open space-time formation, the sense of openness is mostly conveyed through the use of "long shots, mobile framing, and long takes that situate the characters within their open settings, preserving their spatiotemporal integrity" (Naficy 2001: 153). In this sense, it is quite obvious that the open-space time form is manifestly present in the scene. Another aspect of the accented feature in the scene is the portrayal of the vast open field itself. Naficy (2001) argues that the cinematic spaces that usually rendered in the accented films are "gendered," for instance, "the outside, public spaces of the homeland's nature and landscape are largely represented as feminine and maternal" (Naficy 2001: 154). Congruent to the gendered characteristics of the accented spaces, Ratnam's mise-en-scène gives much focus to the natural and scenic attributes of the spaces. For instance, the portrayal of open settings such as the open field. Here, the open field is rendered with aesthetic features, such as splendour, vastness and lushness to indicate the maternal-feminine disposition of the homeland. The maternal-feminine manifestation is also strengthened with a Gregorian chant that melodiously plays with a soothing female voice.

The following scene is presented through the song Grant Me Farewell, My Land (Rahman, Vidai Kodu Engal Naadae), the scene is expressed through the South Indian Tamil version of an Eelam-Tamil song. The scene also goes without any spoken dialogues. The open space-time formation in this scene is expressed through the vast landscape of Maankulam, a native Eelam-Tamil village in the northern region of Sri Lanka. The use of airborne long mobile shots effectively covers the entire landscape of Maankulam and present the exhaustive view of the widely spread natural hills, gravel roads and a long winding river. Although the mise-en-scène of Maankulam unequivocally appears consistent with the open space-time formation, however, the formation is presented with certain flaws. 
In this scene, the sense of spatial openness does not correlate with the sense of timelessness and boundlessness. The landscape of Maankulam is also presented with the sense of constriction, restriction, anxiety, agitation and fear. According to Naficy, one the main aspects of the open space-time formation is the compulsory use of the bright natural lighting scheme. Though the lighting scheme in this scene appears rather natural, it lacks the sense of brightness and warmth, making the landscape appear dark and gloomy. The depiction of the glum atmosphere of Maankulam suppresses the sense of boundlessness and timelessness, a significant property of the open space-time formation. According to Naficy, there are certain exceptions where the open space-time formations are forced to coexist with other space-time formations. In this case, the darkness and gloominess indicate the intrusion of the closed spacetime formation. The absence of the sense of boundlessness and timelessness foreshadow the looming threats and dangers that await Maankulam before long.

\section{THE CLOSED SPACE-TIME FORMATION}

In the first scene, the imminent military invasion establishes the formation of the closed space-time. The mise-en-scène reveals the "interior locations and closed settings, such as prisons and tight living quarters, a dark lighting scheme that creates the mood of constriction and claustrophobia, and characters who are restricted in their movements and perspective by spatial, bodily, or other barriers" (Naficy 2001: 153). In the scene, when Dhileepan and Shyama became aware of the growing sound of the approaching assault tanker, especially from its dreadnaught wheels, both quickly hide.

The following part of the scene brings the view of military encroachment. The growing presence of the impending military force also establishes the film's central trauma. The scene is mostly presented through a combination of close-ups, static and medium shots. Ratnam's screenplay appears to be quite descriptive of the tanker's dreadnaught wheels as it crushes the natural vegetation on its path. The brief yet impactful scene establishes the presence of destruction that is about "devastate" the Eelam-Tamil homeland. The miseen-scène is evidently coherent with the specifications of the closed spacetime form. The scene renders the sense of danger, trauma, fear and panic that creates the "mood of constriction and claustrophobia" (Naficy 2001: 153). The final part of this scene brings a quick view of a cluster of trees facing the river. Since the view of the trees is presented through the single medium-range 
static shot, the mise-en-scène only reveals the trunks, the top and the bottom parts of the trees are not exposed. The view of these bare clustered tree trunks bears the uncanny resemblance of the vertical prison bars. The mise-en-scène establishes the prefiguring of the hostile imprisonment awaiting the dwellers of the native Eelam-Tamil homeland of Sri Lanka. The subsequent frame in this scene renders the unforeseen capture of Thiruchelvan and Wickramasinghe while they were walking through an open field in a rural setting. The scene denotes the notion of uncertainty and threat that lies within the homeland. In this part of the scene, the characters, Thiruchelvan and Wickramasinghe face a brief sense of imprisonment in the hands of the Eelam-Tamil rebels. The capture of the two characters denotes an intensely claustrophobic experience that is driven by fear, panic and trauma. The scene, especially the framing techniques of the claustrophobic experience is indeed consistent with the spatial characteristics of the closed space-time formation.

The next scene is composed using a flashback technique. Generally, in filmmaking, flashbacks are considered as the "cinematic representations of memory and history" (Hayward 2013: 159). Flashbacks are also referred to as "privileged moments in unfolding that juxtaposes different moments of temporal references" (Turim 2013: 1). In the film, Thiruchelvan's flashback brings to the screen the view of a few Eelam-Tamil refugees stranded on what appears to be a narrow-strip-of-land by the sea. The spatial imagery created through Thiruchelvan's flashback demonstrates the existence of the EelamTamil refugees and the miserable state of an open-air refugee camp at the shores of Rameswaram. Although the surroundings of the refugee camp, the open sky and the open sea, somewhat denotes the sense of openness and boundlessness of the open space-time formation, the view of the stranded refugees on a narrow space, dull grey skies and poorly lit mise-en-scène strongly implies the prominence of the closed space-time formation. In this conflation, the closed space-time evidently dominates the mise-en-scène.

The diegetic narrator (Thiruchelvan's voice) underlines the parallel sense of displacement and emplacement experienced by the Eelam-Tamil refugees "in the manner in which the characters occupy the space or are occupied by it" (Naficy 2001: 154). The scene ironically points out the opposition between the closed space-time formation which is set against the open space-time formation, the contrast between the two space-time formations establishes the difference between the lost homeland and the new host land. The mise-en-scène of the refugee camp stands as a typical manifestation of the closed space-time formation; it not only denotes most of the characteristics of the spatial closedness, it also establishes the notion of non-belonging and unhomeliness. 
The fourth scene renders the overpowering presence of the military during the forced evacuation process of the Eelam-Tamils from Maankulam. The mise-en-scène is arranged in such a way that the military presence is visible and felt from every direction. In the scene, the forced evacuation of the Eelam-Tamils from Maankulam is closely monitored and controlled by the military force. The mise-en-scène shows several military vehicles forming barriers restricting the people from moving away from the military controlled route. The scene also shows an assault helicopter hovering watchfully as the Eelam-Tamils slowly make their way out of their native land. The presence of the military represents the sense of oppression that is driven by the phobic fears that emanate from the fundamental nature of the closed space-time formation. The sense of constriction and suffocation is also established through the visual renderings of heavily cramped and overcrowded vehicles that are used to carry the evacuees away from their homeland. In fact, all the scenes that are composed according to the closed space-time formation have one common similarity, that is, these scenes do not include spoken dialogues. The selected scenes are presented solely through the spatial representations. Importantly, these closed space-time structures are consistent with the accented filmmaking strategy, especially in term of evoking the sense of "imprisonment and tight living quarter that creates a mood of constriction and claustrophobia, where the characters are restricted in their movements and perspective by spatial, bodily or other barriers" (Naficy 2001: 153).

\section{THE CONTRADICTORY FORMATIONS OF THE OPEN AND THE CLOSED SPACE}

Based on Naficy's delineation of the preoccupation with the homeland, the scene which renders the capture of Thiruchelvan and Wickramasinghe demonstrates a rare and unusual spatial configuration. The scene shows both the characters encounter an unforeseen imprisonment while they were walking freely through an open field on a bright day. The mise-en-scène establishes the spatial qualities of the openness through the portrayal of the vast, beautiful and rich landscape of the Tamil homeland in Sri Lanka. As opposed to the usual projection of the open space-time formation, the sense of openness in this scene exhibits the striking presence of the closed space-time form. The depiction of the closed space-time formation is expressed through the sense of constriction in the form of entrapment and captivity followed by claustrophobic experiences coupled with the sense of panic, fear and trauma. The incarceration experienced by both Thiruchelvan and Wickramasinghe in 
the hands of the rebels cinematically freezes the mobile framing feature of the open space-time formation to a halted position. The halted, stationary or static framing is a significant attribute of the closed space form. Therefore, in this frame, the closed space-time formation is positioned within the open space-time formation, creating a conflation that demonstrates the notion of conflict. However, both formations also effectively reflect the filmmakers' preoccupation with the place. In this scene, Ratnam uses the representations of the closed space-time formations to convey the notion that the Eelam-Tamil homeland is a controlled and restricted territory where the Eelam-Tamils are destined to live in fear in the restricted homeland. The decussation of the open and the closed space-time formations aesthetically reveals the realistic environment of the Eelam-Tamil homeland of Sri Lanka.

\section{THIRD SPACE-TIME FORMATION}

In the first scene, upon witnessing the military encroachment, Dhileepan and Shyama had no other choice but to part ways. The parting scene takes place at the river, the separation of both the characters is revealed through the use of combined long and medium shots. In this scene, the river functions both as the transitional site and the border. Based on Naficy's description of the third space formation, the materialisation of transitional sites such as the borders and liminal spaces is solely attributed to human engagements such as "border crossing and journeying" (Naficy 2001: 154). In this scene, the manifestation of the river effectively conveys both these ideas. In an exclusive interview published in The Middle East Magazine, director Bahman Ghobadi explains the significance of the borders rendered in his award-winning accented film, A Time for Drunken Horses. According to Kutschera (2003), Ghobadi equates the borders and the spaces associated with them as the "worst enemies of men" (Kutschera 2003: 59).

In this scene, the river which is rendered as the primary manifestation of the third space-time formation establishes the engagement of the journey experiences and border crossings for both the characters. The use of the river imagery to enforce the existence and the influence of the third spacetime formation is consistent with Naficy's observation on Ann Hui's climax sequence in the film, the Song of the Exile (Ke tu qiu hen, dir. Ann Hui 1990). Ann Hui's climax takes place at the border by the sea. Using Ann Hui's film as an example, Naficy argues that the scenes that depict transitional and border spaces are inherently cathartic. Most cathartic scenes are sites of psychological reliefs. These scenes mostly evoke confessions, open expressions or outburst 
of emotions. Similar to the climax scene in Ann Hui's film, Dhileepan and Shyama's separation takes place at the river where both are forced to go their separate ways. The scene is also inherently cathartic, as this is the space where Dhileepan declares to Shyama that he has to leave her for the greater good of their people. In this scene, the river stands as a transitional site and as the border for both characters. Consistent with the characteristics of the third space-time formation, the fluidity of the river does not convey the notion of permanence or stability, this is where Dhileepan and Shyama see each other for the last time. The use of transitional and border space to render the separation of both the characters strongly affirms that the strategy at work in this scene is undoubtedly the one of the accented. The tragic separation of Dhileepan and Shyama reinforces the notion that the representations of the third space-time formation not only profess the notion of impermanence and danger, they also manifest as unpredictable spaces.

The next scene that demonstrates the characteristics of the third spacetime formation is the scene that renders Thiruchelvan's flashback. Unlike the manifestation of the third space-time formation in the previous scene, in this scene, the third space-time formation involves transnational sites. According to Naficy, transnational spaces are perceived as "privileged sites that effectively express the notions of journeys" (Naficy 2001: 5). In terms of disposition, the transnational spaces are quite similar to the transitional and border spaces, except for the reason that transnational spaces involve external experiences, such as journeys across and border crossings. The scene begins with a medium group shot that brings the dark and gloomy imagery of a few stranded Eelam-Tamil refugees on narrow-strip-of-land by the sea. The imagery reveals the predicament of the Eelam-Tamil refugees who have left their homeland, crossed the international borders, but they remain confined in the restricted and liminal space of the refugee camp. In this sense, the refugee camp is represented both as a suspended realm and a transnational site where the film's narrative unfolds through the revelations of the diegetic narrator. The representation of the refugee camp expresses the negative consequences of occupying a transnational site and at the same time poses a threat, that the involvement with these space through journeys and crossings may result in perpetual perilous outcomes.

The third space-time formation is also manifestly dominant in the final scene, Grant Me Farewell, My Land. Similar to the first scene, this scene engages the transitional sites and border spaces as the representations of the third space-time formation to express the inland journeys and border crossings. The inland journey is rendered through the use of hovering mobile, 
medium and close-up shots which allow the comprehensive view of the forced evacuation out of Maankulam. In this scene, the transitional and borders sites are established through the imagery of the river. The scene expressively indicates the forced expulsion of the Eelam-Tamils away from their ancestral Eelam-Tamil homeland, but they do not cross the state borders. In most accented films, especially the exilic ones, the inland journeys and crossings usually do not involve transnational spaces. However, these journeys and crossings do mostly involve transitional and border sites. The theory of the accented cinema distinguishes the journeys and crossings based on their motivation, according to Naficy "journeys may take the form of exploration, pilgrimage, escape, emigration, or return" (Naficy 2001: 222). In this regard, the scene establishes the journey of escape. Based on the audio lyrics of the song Grant Me Farewell, My Land. The scene shows the forceful evacuation of Maankulam which is about to be destroyed by the military, the view of the villagers vacating their homes and leaving Maankulam evokes the notion that the Eelam-Tamil exodus has begun. Besides escaping the imminent military attack, the journey out of Maankulam also involves the perilous experiences of inhabiting transitional and border spaces. The song Grant Me Farewell, My Land reveals the intensity of occupying these impermanent, dangerous and unpredictable spaces.

\section{CONCLUSION}

Inspired by Hamid Naficy's theorisation of an accented cinema, the paper has critically examined four selected scenes from the film Kannathil Muthamittal. The mise-en-scène of selected scenes are indeed consistent with Naficy's spatial representation modality which entails the open, closed and third spacetime formations. Importantly, these space-time formations illustrate the main concern of this analysis which is to determine that the styles and the thematic preoccupation that is particularly associated with the accented cinema had manifestly prevailed in the film, particularly, in the four scenes discussed. According to the theory of an accented cinema, the accented filmmakers' emotional attachment to the spaces and places determines the cinematic dispositions of the space-time formations. However, director Mani Ratnam, a national filmmaker, who is well known for his blockbuster commercial films had derived a particular strategy from the accented filmmaking style, namely, the spatial representation, to express the displacement and deterritorialisation of the Eelam-Tamils ethnic of Sri Lanka. Although the strategy is distinct and 
had never been employed in South Indian Tamil cinema, director Ratnam has effectively used the strategy to create the ambience of displacement and deterritorialisation. For the most part, Ratnam's strategy focuses on the accent which is revealed through the film's spatial representations. The particular strategy is specifically employed to create the exilic spaces and atmosphere, mainly, the environment, atmosphere and landscapes. The rendering of spatial representations in the film appears to be cinematically composed in line with the accented cinematic features, especially, through the use of exclusive camera shots, lighting schemes, spatial specifications, diegesis narrations and the flashback technique. Based on the use of these accented features in the film, the paper substantiates the fact that the South Indian Tamil popular films are also capable of producing artistic film scenes that only meticulously depict the spatial aspects of civil-war ravaged landscapes of Sri Lanka but also the Eelam-Tamil refugee enclosure of Tamil Nadu. The employment of the accented cinematic features effectively produces in-depth meanings of the issues related displacement, such as non-identity and unbelonging. The employment of the accented features in a popular film such as Kannathil Muthamittal is a clear indication that the South Indian Tamil cinema has indeed embarked on a path towards a more progressive form of filmmaking. The paper strongly suggests that as an emerging genre, the accented filmmaking style, if not defined in rigid terms, could offer a whole new perspective to commercial filmmaking, be it, the national or world cinema.

\section{NOTES}

* Ramesh Loganathan holds a Teaching Certificate in English Studies from Maktab Perguruan Kota Bharu, Kelantan, Malaysia. He received his bachelor's degree in education majoring in Teaching English as a Second Language (TESL) and a master's degree in arts majoring in English literature from the University of Malaya, Malaysia. $\mathrm{He}$ is currently pursuing his $\mathrm{PhD}$ in the field of Postcolonial Literature at Universiti Kebangsaan Malaysia.

** Shanthini Pillai $(\mathrm{PhD})$ is an Associate Professor and the Head of the Literature in English Programme at the School of Language Studies and Linguistics, Faculty of Social Sciences and Humanities, Universiti Kebangsaan Malaysia (UKM), Malaysia. Her research interests include diaspora and transnationalism in literary and cultural texts, literature in the real world and multimodality and higher education literature learning. She is the author of Colonial Visions, Postcolonial Revisions: Images of the Indian Diaspora of Malaysia. She also has numerous articles in various areas of literary studies, is a recipient of the 2006-2007 Australia-Malaysia Institute Fellowships and the 2013 Asia Research Institute Visiting Senior Research Fellowship. 
*** Pramela Krish $(\mathrm{PhD})$ is an Associate Professor at the School of Language Studies and Linguistics, Faculty of Social Sciences and Humanities, Universiti Kebangsaan Malaysia (UKM), Malaysia. She specialises in online language learning, qualitative social research, educational technology and language education.

\section{REFERENCES}

Bakhtin, M. M., Holquist, M. and Emerson, C. 2010. The dialogic imagination: Four essays. Texas: University of Texas Press.

Baskaran, S. T. 1996. The eye of the serpent: An introduction to Tamil cinema: Madras: East West Books.

Ceylan, N. B. 2002. Uzak (Distant). Turkey: Mongrel Media.

Dhananjayan, G. 2014. Pride of Tamil cinema: 1931 To 2013: Tamil Films that have earned national and international recognition. Chennai: Blue Ocean Publishers.

Fowler, C. and Helfield, G. 2006. Representing the rural: Space, place, and identity in films about the land. Detroit: Wayne State University Press.

Ghobadi, B. 2002. Zamani barayé masti asbha (A time for drunken horses). Paris: MK2 Productions.

Gow, C. 2011. From Iran to Hollywood and some places in-between: Reframing postrevolutionary Iranian cinema. New York: I. B. Tauris,

Hanson, L. 2009. Edgelands aesthetics: Exploring the liminal in Andrea Arnold's Fish Tank. Writing Visual Culture 6: 1-19.

Hayward, S. 2013. Cinema studies: The key concepts. Abingdon: Routledge.

Hui, A. 1990. Ke tu qiu hen (Song of the exile). Hong Kong: Cos Group.

Kar-wai, W. 1997. Chun gwong cha sit (Happy together). Hong Kong: Block 2 Pictures.

Kutschera, C. 2003. The pain of giving birth to Kurdish cinema. Middle East 339: 56-59.

Moodley, S. 2003. Postcolonial feminisms speaking through an 'accented' cinema: The construction of Indian women in the films of Mira Nair and Deepa Mehta. Agenda 17 (58): 66-75.

Naficy, H. 2001. An accented cinema: Exilic and diasporic filmmaking. New Jersey: Princeton University Press.

Nagappan, R. 2011. Speaking havoc: Social suffering and South Asian narratives. Washington: University of Washington Press.

National Film Development Corporation of India (NFDC). 1991. Indian cinema: Directorate of film festivals. Mumbai: Ministry of Information and Broadcasting Publications Division.

Pandian, A. 2011. Landscapes of expression: Affective encounters in South Indian Cinema. Cinema Journal 51 (1): 50-74, https://doi.org/10.1353/cj.2011.0078.

Prince, G. 2003. A dictionary of narratology. Nebraska: University of Nebraska Press.

Rahman, A. R. 2002. Vidai Kodu Engal Naadae (Grant me farewell, my land). Chennai: Panchathan Record Inn and AM Studios, B009A9VPYM.

Ratnam, M. 1992. Roja (Rose). Chennai: Kavithalayaa Productions. 1995. Bombay (Bombay). Chennai: Aalayam Productions. 
Ratnam, M. 2002. Kannathil muthamittal (A peck on the cheek). Chennai: Madras Talkies. Suner, A. 2006. Outside in: "Accented cinema" at large. Inter-Asia Cultural Studies 7 (3): 363-382, https://doi.org/10.1080/14649370600849223.

Taylor, H, 2015. Refugees and the meaning of home: Cypriot narratives of loss, longing and daily life in London. Hampshire: Palgrave Macmillan, https://doi. org/10.1057/9781137553331.

Turim, M. 2013. Flashbacks in film: Memory and history. Abingdon, Oxfordshire: Routledge.

Velayutham, S. 2008. Tamil cinema. Hoboken: Taylor \& Francis. 